\title{
El pensar histórico como genealogía: acto interpretativo y construcción de subjetividad
}

\author{
María del Pilar Melgarejo Acosta \\ Pontificia Universidad Javeriana \\ Universidad de los Andes \\ Resumen
}

El presente artículo pretende aproximarse desde una perspectiva filosófica a un carácter particular del pensar histórico: la genealogía. Se trata de una reflexión acerca del modelo genealógico no sólo como análisis histórico, donde la mirada del historiador es comprendida como acto interpretativo, sino como generador de saber y productor de subjetividad. La genealogía abre la posibilidad de que las ciencias sociales puedan reconocerse como labor histórica para repensar así los modos en que problematizan su presente.

\begin{abstract}
Through a philosophical perspective, this article attempts to approach a specific character of historical thinkins genealogy. It is a matter of reflecting about the genealogical model not only as historical analysis, where the historian' s gaze is understood as interprete ve act, but also as knowledge generator and subjetivity producen Genealogy opens up the posibilíty that the social sciences recognize themselves as historical work, thus rethinking the ways in which they themselves problematize their own present.
\end{abstract}

María del Pilar Melgarejo Acosta. "El Pensar Histórico Como Genealogía Acto Interpretativo y Construcción de Subjetividad." (La versión original de este artículo fue presentada como ponencia en el panel Para una Genealogía de las Ciencias Sociales en Colombia, en el XI Congreso Colombiano de Historia, Universidad Nacional de Colombia, Bogotá, agosto de 2000). 


\section{FRONTERAS}

de la histosia

"La historia no existe; sólo existen 'historias de...' Lahistoriano tiene método, pero tiene una crítica y sobre todo una tópica. Los 'hechos' no existen; sólo existen intrigas. ¿Existen, al menos, los documentos?No, también son acontecimientos... La historia no explica. No, pero ella es explícita. ¿Existen leyes de historia? No; como mucho, existen leyes en historia. ¿Es la historia una ciencia? No, es una actividad intelectual. ¿Es entonces una existencia, conciencia histórica o historiadora? No, es conocimiento...

Entendámonos bien. No basta con afirmar una vez más que la historia habla de 'lo que jamás se verá dos veces'; tampoco se trata de afirmar que es subjetividad, perspectivas, de que interrogamos al pasado a partir de nuestros valores, de que los hechos históricos no son cosas, de que el hombre se comprende y no se explica, de que no puede tener ciencia de sí mismo. En una palabra, no se trata de confundir el ser y el conocer... ¿Qué es la historia entonces? ¿Qué hacen realmente los historiadores cuando han dejado sus documentos y se disponen a hacer la 'síntesis' ?... los historiadores narran acontecimientos verdaderos que tienen al hombre por actor; la historia es una novela verdadera". ${ }^{1}$

"El saber no está hecho para comprender, está hecho para zanjar".2

La presente reflexión es una aproximación a un carácter particular del pensar histórico: la genealogía. Este tipo de análisis histórico se pregunta cómo es que hemos llegado a ser lo que somos y cuáles son las formas que han permitido el que hoy en día nos podamos pensar de determinadas maneras y no de otras, lo cual consiste en un rastreo que permita desobjetivar los conceptos a partir de los cuales la historia ha sido narrada y mediante los cuales los hombres se han definido. Esto implica abrir la posibilidad de poder extrañarnos frente al pasado, desnaturalizando el acontecimiento.

La genealogía no pretende describir génesis lineales concebidas en función de lo útil, "como si las palabras hubiesen guardado su sentido, los deseos su dirección, las ideas su lógica; como si este mundo de cosas dichas y queridas no hubiese conocido invasiones, luchas, rapiñas, disfraces, astucias". ${ }^{3}$ De acuerdo con Foucault, lo que

\footnotetext{
${ }^{1}$ Paul Veyne, Cómo se Escribe la Historia: Ensayo de Epistemología (Madrid: Fragua, 1972), 5.

${ }^{2}$ Michel Foucault, Nietzsche, la Genealogía, la Historia (Valencia: Pretextos, 1997), 47.

${ }^{3}$ Ibid., 11.
} 
pretende la genealogía es localizar la singularidad de los acontecimientos, desprovista de una perspectiva evolucionista.

Indagar por el sentido histórico desde una mirada genealógica supone un redescubrimiento meticuloso de las luchas y una memoria de los enfrentamientos que les abra paso a aquellos saberes que se encuentran al margen de los discursos totalizantes. "Las fuerzas que están en juego en la historia no obedecen ni a un destino ni a una mecánica, sino al azar de la lucha... No se manifiestan como las formas sucesivas de una intención primordial; tampoco se presentan con la apariencia de un resultado. Aparecen siempre en el azar singular del acontecimiento". 4

De tal forma que la pregunta de la presente reflexión pretende aproximarse desde una perspectiva filosófica al trabajo histórico, a la encrucijada en la que se ve envuelto el historiador cuando vuelve objeto la práctica, el discurso, el acontecimiento o acaso un tipo de racionalidad. Esta pregunta está dirigida a los modos de hacer historia, a las miradas que atraviesan y generan rupturas y fisuras en el saber, al juego de tensiones que pervierte las reglas de los discursos, a las continuidades y discontinuidades que gestan distintos tipos de desplazamientos, a las maneras en que la pregunta por la historia es la pregunta por nosotros mismos.

Me interesa, en primera instancia, abordar la mirada histórica como acto interpretativo, es decir, las distintas perspectivas para pensar la historia que nos ofrece la cuestión de la interpretación. Este giro conceptual, esta forma de mirar la historia, en tanto multiplicidad, permite establecer el puente con el modelo genealógico como análisis histórico, un modelo que parece acercarse a la paradoja, es decir, descubrir lo más oculto: aquello que es evidente, las prácticas. Pero la relación entre genealogía e historia no se agota en el ámbito metodológico, este modo de trabajo histórico es generador de saber, produce cierto tipo de conocimiento acerca de la historia y de los hombres. En este sentido, la genealogía devela al hombre mismo como un falso problema, poniendo en duda la cuestión misma de individuo y apostando por una noción de hombre distinta, en tanto producción de subjetividad histórica.

\footnotetext{
${ }^{4}$ Friedrich Nietzsche, Genealogía de la Moral, pt. 2 (Madrid: Alianza, 1994), 12.
} 


\section{La mirada histórica como acto interpretativo}

La crítica de Nietzsche, ${ }^{5}$ a la naturaleza de los estudios históricos de su tiempo siglo XIX- resulta pertinente en la medida en que permite elaborar una reflexión acerca de las herramientas que han conducido y de alguna manera conducen el pensar histórico. Nietzsche discutía tanto con idealistas como con positivistas; con quienes indagaban por un saber absoluto de la historia y los que pretendían fundamentarla con los métodos de las ciencias naturales. Lo que Nietzsche criticaba era el punto de vista suprahistórico encontrado tras estas dos concepciones, el cual entendía que la historia tenía la función de recoger en una totalidad bien cerrada sobre sí misma, la diversidad del tiempo. Esta concepción de la historia permite un reconocimiento de la misma como reconciliación. De acuerdo con Foucault, "... esta historia pretende juzgarlo todo según una objetividad apocalíptica; y es que ha supuesto una verdad eterna, un alma que no muere, una conciencia siempre idéntica a sí misma."

"El sentido histórico escapará a la metafísica, para devenir el instrumento privilegiado de la genealogía, si no se apoya sobre ningún absoluto. Sólo debe ser esa agudeza de una mirada que distingue, distribuye, deja actuar las desviaciones y los márgenes; una especie de mirada disociante capaz de disociarse ella misma y de borrar la unidad de ese ser humano supuestamente capaz de llevarla soberanamente hacia su pasado."

Según Nietzsche, la enfermedad histórica que padecían los historiadores de su tiempo estaba referida a un exceso de conciencia historiográfica, característico del siglo XIX, el siglo de los Estados nacionales, la cual generó incapacidad para crear una nueva historia, una nueva manera de narrar lo acontecido. La exigencia que la historia sea ciencia, su absolutización, ha agotado la posibilidad de que esta sea

\footnotetext{
${ }^{5}$ Friedrich Nietzsche, Segunda Consideración Intempestiva: De la Utilidad y los Inconvenientes de la Historia para la Vida en Antología, Textos Cardinales, trad. José Llinares Chover y Germán Meléndez, no. 8 (Barcelona: Península, 1988).

${ }^{6}$ Foucault, Nietzsche, 44.

${ }^{7}$ Ibid.
} 
comprendida sólo en tanto su relación con la vida, con la contingencia. De tal modo que la crítica a la "objetividad" historiográfica es la crítica a la pretensión de aplicar al conocimiento historiográfico el ideal metódico de las ciencias de la naturaleza.

En palabras de Paul Veyne, la historia es conocimiento mutilado, el historiador no dice lo que son o fueron los hechos, más bien puede narrar lo que hoy podemos saber todavía de ellos. Pero la narración de tal historia es principalmente una posible lectura de las múltiples que puede arrojar un mismo acontecimiento, su narración lo vuelve objeto, pero él no es un objeto en sí mismo. La historia es historia de las relaciones, de configuraciones sucesivas, no de sujetos o de objetos, son las relaciones las que van determinando los distintos elementos a los cuales la historia se refiere.

Para Nietzsche toda historia es una interpretación, el pasado surge en la medida en que se interpreta, es una posición de sentido, pero no todas las interpretaciones tienen el mismo valor. De tal manera que la genealogía debe ser la historia de dichas interpretaciones, donde el acto de interpretar supone apropiarse violentamente de un sistema de reglas que en sí mismo no tiene significación esencial, e imponerle una dirección, hacerlo entrar en otro juego y someterlo a reglas secundarias. Romper con la idea de una historia universal no sólo supone dejar sin sustento el modelo metafísico, sino reconocer la existencia de múltiples historias en tanto culturas y múltiples formas de narrar según los diferentes momentos de dichas historias. $^{8}$

Según afirma Paul Veyne, los historiadores narran acontecimientos verdaderos que tienen al hombre como actor, lo cual supone comprender los hechos como acontecimientos que se consideran interesantes en sí mismos. Mas si nos interesamos por

\footnotetext{
${ }^{8}$ E1 hombre actual se ha dado cuenta de que la historia de los acontecimientos -políticos, militares, grandes movimientos de ideas- es sólo una historia entre otras; a esta historia se le puede contraponer, por ejemplo, la historia de los modos de vida, que se desarrolla mucho más lentamente y se aproxima casi a una 'historia natural' de las cuestiones humanas... la aplicación de los instrumentos de análisis de la retórica a la historiografía ha mostrado que en el fondo la imagen de la historia que nos forjamos está por entero condicionada por las reglas de un género literario, en suma, que la historia es 'una historia', una narración, un relato mucho más de lo que generalmente estamos dispuestos a admitir." Gianni Vattimo, El Fin de la Modernidad, Nihilismo y Hermenéutica en la Cultura Posmoderna (Barcelona: Gedisa, 1996), 27.
} 
su carácter repetible, se trataría sólo de un pretexto para descubrir una ley. El acontecimiento de ningún modo es captado directamente, sino incompleta y lateralmente. Los hechos históricos son interpretaciones que realizan los hombres y la historia, en este sentido, no es más que un relato de acontecimientos con pretensión de verdad. Es el sentido histórico del acto intepretativo el que configura las diversas formas de narrar.

El sentido histórico que se libera de la historia suprahistórica, explicado por Foucault desde Nietzsche, posee tres usos: el uso paródico y destructor de realidad, que se opone a la historia-reconocimiento, el uso disociativo y destructor de identidad, que se opone a la historia-continuidad y el uso destructor de verdad que se opone a la historiaconocimiento. En las Intempestivas, Nietzsche le objeta a la historia el riesgo de impedir toda creación en nombre de la ley de fidelidad. Si la conciencia histórica se interroga a sí misma e interroga, al mismo tiempo, a toda conciencia científica en su historia, puede percatarse de que el querer-saber del análisis histórico no posee un fundamento de lo verdadero y en lugar de generar seguridades agudiza y multiplica los riesgos.

De manera pues, que la distancia impuesta entre los hombres y la historia elimina la posibilidad de que esta última pueda ser comprendida en tanto pertenencia y no en tanto objeto exterior. De acuerdo con Nietzsche, el conocimiento histórico pareciera plantearse a priori como la superación de una distancia temporal. La crítica que se encuentra en la base de este punto, va dirigida a que el sentido histórico olvide su carácter epocal para convertirse en norma, lo que implica que las categorías del conocimiento científico moderno -neutralidad valorativa o preeminencia de los hechos- pretendan extenderse de manera ilimitada. En este sentido, la genealogía se opone al desplegamiento metahistórico de las significaciones ideales y de las indefinidas teleologías.

Las pequeñas verdades que se van forjando a lo largo del recorrido histórico, más que describir reconstructivamente un proceso, ponen en juego las fuerzas interpretativas en tensión. La verdad es, en este contexto, la potenciación del pro ceso interpretativo. En este sentido, conocer es interpretar e interpretar es producir una nueva historia. De acuerdo con lo anterior, ¿no es la historia ya una interpretación que como tal no puede reclamar evidencias o visiones incontrovertibles a su 
favor? La historia en tanto narración, sólo puede ser producto de las relaciones de poder que se mantienen entre unas perspectivas y otras, donde la multiplicidad de sentidos está sujeta a la dominación temporal de una fuerza particular. La genealogía intenta, entonces, descubrir el velo metafísico de aquellas tramas epistémicas, que en tanto interpretaciones, sedimentan las formas de comprensión.

Desde Nietzsche, interpretar significa en primer lugar, la actividad por la que todo ser orgánico constituye la realidad, no es posible sustraerse de ella, pues es la actividad que constituye la vida misma, ya que esta sólo es posible en un horizonte interpretado. Hay que tener presente en segundo lugar, que la interpretación no es la acción de un sujeto autónomo, ésta es generada por un sujeto producto de sus experiencias pasadas. En tercera instancia, la interpretación es un proceso de reinterpretación que no tiene final, como no existe una realidad en sí, la actividad interpretativa es infinita. "La interpretación es la vida y la realidad mismas, no un comportamiento más de la vida para conocer esa realidad... Los instintos sólo interpretan desde una experiencia guardada y en esa medida toda interpretación no hace más que apropiarse de una interpretación previa, reconfigurándola de acuerdo con las nuevas necesidades en juego". ${ }^{9}$ Por último Nietzsche hace una exigencia: las interpretaciones deben proliferar, es decir, es preciso ampliar la perspectiva para gestar nuevos modos de conocimiento, aunque para Nietzsche, mucho más que eso, la actividad interpretativa es una actividad vital, lo que se pone en juego es la fuerza de la vida, "pues toda presunta verdad absoluta significa la muerte de la interpretación y, por ello, de la vida misma". ${ }^{10}$ Dentro de este contexto, ¿cómo no pensar la historia en tanto proliferación de interpretaciones?

En este marco, es preciso no perder de vista que tras el acto de interpretación histórica subyace un fondo valorativo que permea la narración histórica y que va dibujando el perfil de lo que entendemos por pasado. Asumir radicalmente las implicaciones de una comprensión de la historia, en tanto interpretación, supondrá un rastreo del carácter epocal de las valoraciones. Tratar de evidenciar el proceso por el cual una valoración se ha hecho dominante, indagar por la génesis de nuestras valoraciones y creencias actuales es el propósito del método genealógico.

\footnotetext{
${ }^{9}$ Luis Eduardo Gama, "Nietzsche y la Cuestión de la Interpretación" (ponencia presentada en el curso de extensión Nietzsche 100 Años, Universidad Nacional de Colombia, Bogotá, 2000), 8.

${ }^{10}$ Ibid., 9.
} 


\section{FRONTERAS}

Mientras la historia conserve su carácter de apertura, mientras disponga horizontes de sentido que vehiculen perspectivas mas no dogmaticen visiones profundas, las posibilidades del pensar histórico podrán ser ampliadas. Pensar la historia en tanto interpretación modifica las maneras de mirar el presente y por lo tanto de comprender no sólo cómo se han configurado las naciones, los estados, los poderes y las instituciones, sino más aún, cómo nos hemos configurado como sujetos.

\section{El modelo genealógico como análisis histórico}

"Seguir el hilo complejo de la procedencia es, al contrario, conservar lo que ha sucedido en su propia dispersión: localizar los accidentes, las mínimas desviaciones -o contrariamente, los giros completos-, los errores, las faltas de apreciación, los malos cálculos que han dado nacimiento a lo que existe y es válido para nosotros, es descubrir que en la raíz de lo que conocemos y de lo que somos no hay ni el ser ni la verdad, sino la exterioridad del accidente".

La genealogía no pretende trazar continuidades, la discontinuidad es el elemento forjador de instrumentos conceptuales y distintos niveles de análisis, en lugar de una historia global que trata de articular todos los fenómenos alrededor de un único centro, una historia general que permite desplegar un campo de dispersión, más exactamente, el metodo genealógico pretende conservado todo en su propia dis-persión, donde lo que se intenta analizar es el juego de las relaciones de dominación y correlación entre los fenómenos y sus diversas permanencias.

En este sentido, pensar las ciencias sociales desde una perspectiva genealógica, supone replantear el corpus de estudio histórico que las venía constituyendo y definir el nivel de análisis y los sistemas que conforman su material histórico. Esta nueva forma de comprensión enfrenta a las ciencias sociales al desafío de configurar formas de racionalidad distintas alejadas de una concepción ahistórica o suprahistórica que impide al hombre, a pesar de toda su metodología científica, comportarse de la misma manera que todo aquel que, como hijo de su tiempo, está dominado acríticamente por los conceptos previos y los prejuicios de su época.

\footnotetext{
${ }^{11}$ Foucault, Nietzsche, 28.
} 
El trabajo científico de las ciencias sociales implica no sólo un proceso de construcción de teorías y trabajo empírico, elaboración de conceptos y formulación de hipótesis susceptibles de verificación en la historia, sino más que eso, su campo exige, de alguna manera un carácter dialéctico que pueda reconocer el movimiento histórico que atraviesa no sólo el conocimiento sino los sujetos que conocen. La substancialización de las estructuras carece ya de sentido, el saber y el sujeto no se inscriben en epistemes fijas, pero tampoco están a la deriva, los contextos y condiciones son determinantes.

La genealogía del presente no consiste en reconstruir el pasado a la luz del presenle, se trata más bien de partir de una cuestión que es problemática en el presente para trazar su génesis. "Pensar históricamente quiere decir, en realidad, realizar la transformación que les acontece a los conceptos del pasado cuando intentamos pensar en ellos. Pensar históricamente entraña en consecuencia siempre una mediación entre dichos conceptos y el propio pensar."12 Para el genealogista, resulta urgente restituir el juego de las interacciones entre saberes y poderes específicos. Su punto de partida epistemológico consiste en poner a prueba las categorías de conocimiento instituidas en el campo científico de las ciencias humanas y sociales, explorar los mecanismos e instituciones de la vida social, sus interdependencias, las prácticas y las tácticas de resistencia.

Michel Foucault y Norbert Elias pueden ser reconocidos como analistas sociales cuyos trabajos sociológicos estuvieron sostenidos sobre tres elementos primordiales: las relaciones de poder, las formas de conocimiento y los procesos de individualización. A pesar de importantes diferencias, los dos teóricos defendían un modo de comprender la historia como la recuperación de la memoria de los conflictos. Tanto Foucault como Elias reivindican una historia que permita analizar la especificidad de los discursos y de las prácticas. Se trata de evitar los recursos reductores que emplean los científicos sociales: el recurso histórico trascendental y el recurso empírico psicológico, para proponer un análisis de las condiciones de formación de las categorías de pensamiento y las transformaciones que las han atravesado.

\footnotetext{
${ }^{12}$ Hans-Georg Gadamer, Verdad y Método (Salamanca: Sigueme, 1984), 477.
} 
Michel Foucault explica cómo "la genealogía es una especie de tentativa para liberar de la sujeción a los saberes históricos, es decir, para hacerlos capaces de oposición y lucha contra la coerción de un discurso teórico unitario, formal y científico, una vía para rechazar los efectos de poder derivados de teorías definidas como científicas, y para eliminar la tiranía de los discursos globalizantes establecidos con sus privilegios y jerarquías institucionales." ${ }^{13}$

Según afirma Paul Veyne, el método al que alude Foucault consiste específicamente en comprender que las cosas no son más que objetivaciones de prácticas determinadas. Es preciso, entonces, poner de manifiesto dichas determinaciones porque la conciencia no las concibe. Pareciera ser que los objetos ordenan nuestra conducta, pero en realidad nuestra práctica determina con anterioridad dichos objetos. El objeto no puede ser entonces sino consecuencia de la práctica, cuando el falso objeto natural se convierte en hecho histórico ya no es objeto más que para una práctica que logra objetivarlo. Cada práctica gesta el objeto que le corresponde.

El obstáculo epistemológico ante el cual nos encontramos es que a la hora de abordar estudios complejos de procesos sociales, los esquemas y conceptos demasiado rígidos no permiten dar cuenta de las transformaciones histórico-sociales. En este sentido, Elias y Foucault intentan romper con las dicotomías de dominantes-dominados, individuo-sociedad, ciencia-ideología, represión-liberación y objeto-sujeto, para pensar mejor en términos de las relaciones de poder y de saber en determinado momento histórico y en un espacio social específico.

Es posible definir el modelo genealógico como un modelo procesual de doble vía.

"Por una parte, se estudian procesos de cambio social en tanto que tales. Se explica así la importancia que cobran los procesos de larga duración para dar cuenta de las reglas de constitución de un campo, las regularidades y las transformaciones. Pero además se trata de desentrañar la lógica interna de funcionamiento de dicho campo, los conceptos y operaciones que lo atraviesan, así como las relaciones que existen entre los discursos y el contexto material e institucional no discursivo".

\footnotetext{
${ }^{13}$ Julia Varela, Nacimiento de la Mujer Burguesa: El Cambiante Desequilibrio de Poder entre los Sexos (Madrid: La Piqueta, 1997), 37.

${ }^{14}$ Ibid.,41.
} 
El genealogista es aquel que pretende desentrañar la lógica interna de la dinámica social sin pretensiones de determinismo y más bien está atento a aquellos factores que se articulan y que permiten explicar los procesos sociales. La mirada genealógica en tanto mirada histórica debe ser una mirada interesada y crítica, es decir, preocupada por las distintas relaciones que se establecen entre los elementos históricos, para lo cual tiene que ser capaz de pensar no en términos de objetos sino mejor, en términos de objetivaciones de las prácticas. Lo que es, podría ser distinto, por eso el genealogista se convierte en el acróbata que es capaz de danzar, de lado a lado, sin moverse en el campo de los absolutos, pero tampoco en el campo de lo radicalmente contingente, manteniéndose en el medio, en el lugar de las prácticas.

\section{Genealogía e historia como producción de saber}

Afirma Nietzsche que el saber es minucioso, se construye a partir de pequeñas verdades sin apariencia, establecidas según un método riguroso. La genealogía mantiene una relación con el saber que no es de ningún modo conciliadora, quiere desgarrarlo, apropiarse de él violentamente. Pero el ejercicio de deconstrucción de las categorías históricas no se agota en las rupturas, violenta las raíces porque pretende desentrañar las lógicas. Esto quiere decir que se enfrenta con lo más evidente, con aquello que está tan cerca que resulta difícil distinguirlo, este es el saber de las prácticas, de los mecanismos que operan en las relaciones sociales en tanto relaciones de poder.

El saber aquí no puede solidificarse y ser pura acumulación, él debe ser más bien un conjunto de fallas, de fisuras, de capas heterogéneas que no buscan fundamentar, sino por el contrario agitar lo que se advertía inmóvil y fragmentar lo que se percibía unido y conforme a sí mismo. El saber que arroja la genealogía no es constituyente sino constituido, se construye y al mismo tiempo se deconstruye constantemente, es urgente entonces, desnaturalizar sus objetos y ser capaces de extrañarse frente a él.

Si se acepta que el saber histórico es ante todo conocimiento mutilado, quiere decir que el pasado puede ser traído al presente no como facticidad sino sólo en tanto aquello que poseemos como registro. En este sentido, no se puede justificar el 
conocimiento partiendo del conocimiento mismo, partiendo de una comprensión de la "verdad" como adecuación del pensamiento con el objeto de conocimiento. "Saber, incluso en el orden histórico, no significa 'reconocer', y mucho menos 'reconocernos' . La historia será 'efectiva' en la medida en que introduzca lo discontinuo en nuestro mismo ser". ${ }^{15}$

La mirada del genealogista es pues una mirada interpretante que sabe desde dónde mira y lo que mira. ¿Pero en el campo de la historia, cuál es la relación que se entabla entre saber y verdad? ¿En qué sentido la historia puede hacerse la pregunta por la verdad? Nietzsche critica la verdad como correspondencia, pues esto supone reconocer las proposiciones como descripciones de una realidad absoluta. La verdad es interpretación, pero al mismo tiempo participa del juego de las interpretaciones genealógicas que muestran cómo ha llegado a constituirse un fenómeno de nuestra realidad. "La verdad no es, pues, algo que estuviese ahí y hubiese de ser encontrado, descubierto, sino algo que hay que crear y da el nombre para un proceso...". ${ }^{16}$ En este sentido, la verdad del saber que produce la genealogía determina de alguna forma el tipo de conocimiento histórico que la misma genealogía arroja. Se trata entonces de indagar por "la historia de las relaciones que anudan el pensamiento a la verdad y la verdad a la historia del pensamiento en tanto pensamiento de la verdad". ${ }^{17}$ Pero esta historia del pensamiento no se agota en la historia de las ideas o de las representaciones, sino que indaga por la constitución de los saberes, es decir, el procedimiento genealógico se pregunta por el modo en que el discurso y las prácticas se gestan de determinadas maneras y no de otras, sin pretender alcanzar algún principio universal.

La larga coacción de la historia ha vuelto a la verdad inalterable,"... la misma cuestión de la verdad, el derecho que se otorga de rechazar el error o de oponerse a la apariencia, la manera en la que sucesivamente fue accesible a los sabios, retirada luego a un mundo fuera de alcance en el que jugó a la vez el papel de consuelo y de imperativo, rechazada finalmente como idea inútil, superflua, en todas partes

\footnotetext{
${ }^{15}$ Foucault, Nietzsche, 47.

${ }^{16}$ Friedrich Nietzsche, Fragmentos Póstumos, trad. Germán Meléndez Acuña, pt. 9 (Bogotá: Norma, 1992$), 105$.

${ }^{17}$ Michel Foucault, Saber y Verdad (Madrid: La Piqueta, 1991), 231.
} 
rebatida, ¿no es todo eso una historia, la historia de un error llamado verdad? La erdad y su reino originario han tenido su historia en la historia". ${ }^{18}$

La voluntad de verdad, con la que los hombres indagan la historia, crea la ilusión de que estos pueden atrapar la verdad como si ésta fuera un objeto exterior, como si al poseerla fuera posible tener control sobre las vicisitudes. No hay en el conocimiento un derecho a la verdad o un fundamento de lo verdadero, "el querer-saber no nos acerca a una verdad universal; no da al hombre un exacto y sereno dominio de la naturaleza; al contrario, no cesa de multiplicar los riesgos; en todas partes hace crecer los peligros; abate las protecciones ilusorias; deshace la unidad del sujeto; libera en él todo lo que se empeña en disociarlo y destruirlo". ${ }^{19}$

Ya no se trata entonces de juzgar el pasado en nombre de una verdad que únicamente posee el presente, se trata mejor, de destruir el sujeto de conocimiento que se ufanara de sí mismo. La genealogía vuelve entonces a tres modalidades de la historia que Nietzsche reconocía en 1874, pero vuelve metamorfoseándolas: la veneración a los monumentos deviene en parodia, el respeto a las antiguas continuidades deviene en eisociación sistemática y la crítica a las injusticias del pasado por la verdad que el hombre detenta hoy, deviene en destrucción del sujeto de conocimiento ${ }^{20}$.

La genealogía restablece los diversos sistemas de sometimiento: no la potencia emancipadora de un sentido, sino el juego azaroso de las dominaciones". ${ }^{21}$ La historia aquí es escenario, lugar de enfrentamiento, juego de intrigas y dominaciones. "Unos hombres dominan a otros, y así nace la diferenciación de los valores; unas clases dominan a otras y así nace la idea de libertad; unos hombres se apoderan de las cosas que necesitan para vivir, les imponen una duración que no tienen, o las asimilan a la fuerza -y nace la lógica-". 22

\footnotetext{
${ }^{18}$ Foucault, Nietzsche, 22.

${ }^{19}$ Ibíd., 71.

${ }^{20}$ Ibíd., 75.

${ }^{21}$ Ibíd., 34.

${ }^{22}$ Ibíd., 38.
} 


\section{FRONTERAS}

delabistosia

Vol 5/2000

\section{Genealogía y subjetividad histórica}

La ruptura dicotómica planteada por el método genealógico no sólo nos enfrenta a nuevos modos de pensar la historia, sino, de manera más radical, nos confronta con la necesidad de elaborar una reflexión más cuidadosa acerca de las formas de subjetivación que se han ido configurando a lo largo de los procesos históricos. La comprensión de los hombres, en tanto sujetos de la historia, no puede oscilar entre un determinismo estructural o acaso una autonomía radical. Los hombres en cada momento actualizan las particularidades de su época histórica. No hay un sujeto originario, la historia misma nos enseña a reírnos de tal solemnidad, pues ella antes que reconciliación es puro accidente. "Lo que encontramos en el comienzo histórico de las cosas no es la identidad aún preservada de su origen -es su discordancia con las otras cosas-, el disparate." ${ }^{23}$.

El sujeto es constituido y constituyente de la historia, produce y se reproduce en cada momento, se mueve en los distintos espacios y participa del juego complejo de los procesos sociales. Gracias a la fuerza de usar el pasado para la vida y de transformar la historia pasada en historia presente, el hombre es capaz de convertirse en hombre, pero tal como afirma Nietzsche, en un exceso de historia, es decir, cuando ella olvida su carácter discontinuo, el hombre cae nuevamente.

La historia no busca perseverar la identidad; muy por el contrario, la genealogía muestra cómo el trabajo histórico puede permitir su disociación sistemática. Su debilidad sobrepasa la pretensión de conservarla intacta y nos pone ante el desafío de pensar la identidad como pluralidad, como el espacio donde se entrecruzan formas de dominación distintas. En este sentido, la apuesta no es por la unidad en tanto sujetos, sino por las distintas fuerzas históricas que nos atraviesan, es por esto que el objetivo de la historia dirigida genealógicamente no es encontrar las raíces de la identidad, sino mejor lograr disiparla sin perder de vista las relaciones que la van configurando en cada momento histórico.

La pregunta por el origen, para el genealogista, resulta vana, pues pretende ser esencialista, quiere establecer límites y olvida lo accidental. Aquí el hombre quiere

${ }^{23}$ Ibíd., 19 
comprometerse a quitar todas las máscaras para desvelar al fin una identidad primera. Allí donde el yo se inventa una identidad o una coherencia el genealogista indaga por los diferentes comienzos. Nietzsche critica precisamente a los historiadores de su tiempo afirmando que erróneamente se considera que el historiador sólo es objetivo en el estado "en que considera... un acontecimiento en todos sus motivos y consecuencias de un modo tan puro que no tiene ningún efecto sobre su yo". ${ }^{24}$ En este sentido, lo que permite la genealogía, de acuerdo con Foucault, es disociar el yo y hacer pulular, en los lugares y posiciones de su síntesis vacía, mil acontecimientos perdidos.

La pregunta por la identidad ya no resulta entonces tan clara, pues se diluye, se pierde, de tal manera que al historiador no le queda más que danzar en el carnaval del tiempo donde las máscaras volverán constantemente. En este sentido, es preciso disolver al sujeto como fundamento para comprenderlo mejor como producto que se gesta en las prácticas que configuran socialmente los espacios institucionales y no institucionales; desde ahí, el sujeto no puede ser más que juego de tensiones. La elaboración de la pregunta por la subjetividad sólo puede ser histórica; pero más allá de esto, las maneras en que pensamos históricamente están relacionadas con formas je percibirnos como sujetos. Más que afirmar que el sujeto se constituye históricamente, la historia no es más que la narración de las distintas subjetividades, es en este sentido en el que el sujeto es una ficción que nos permite enlazar los acontecimientos, sin perder de vista que él mismo es un acontecimiento que transita en la historia.

\section{A modo de conclusión}

La genealogía no busca arrojar respuestas, expone recorridos, aquellas lógicas que subyacen a los procesos sociales, y desde ahí nos pone ante el desafío de cuestionar las categorías a partir de las cuales pensamos la historia y nos pensamos a nosotros mismos.

El relato no sólo produce el sentido, sino que éste es interpretación de un sentido que le precede. La conciencia histórica que devela la genealogía se propone descubrir aquellas formas de comprensión que configuran el horizonte desde el cual

\footnotetext{
${ }^{24}$ Nietzsche, Segunda Consideración Intempestiva, 84.
} 
miramos. Esta debe ser, principalmente, una mirada dispuesta a la metamorfosis, que pueda enfrentarse al desafío de mirar la historia como el cuerpo mismo del devenir.

La historia no es sólo el escenario en que nos forjamos como sujetos, no se trata de descubrir lo que somos sino de rechazar lo que somos, es decir, de procurar la proliferación de nuevas formas de subjetivación. Tal como afirma Bourdieu, siguiendo a Nietzsche y a Foucault, "si es preciso conocer la historia no es tanto para alimentarse de ella cuanto para liberarse de ella, para evitar obedecerla sin saberlo o para evitar repetirla sin quererlo." ${ }^{25}$. De la misma manera, resulta urgente producir nuevas formas de comprensión del sujeto que hagan resistencia a formas prefijadas de individualización y totalización. Esto teniendo en cuenta que el sujeto es construido por determinadas prácticas en el interior de ciertos saberes que se encuentran inscritos en la historia.

La propuesta de una metodología genealógica como alternativa pretende no sólo llamar la atención acerca de la interacción entre teoría y praxis sino fundamentalmente romper las barreras formadas por las disciplinas, para contribuir así a formar comunidades científicas cada vez más abiertas, que logren problematizar radicalmente el presente. Es preciso entonces que las ciencias sociales, más allá de la racionalización de objetos naturales, se reconozcan a sí mismas como labor histórica. Pero el método genealógico que supone dicha tarea implica la actualización de una práctica o discurso.

He pretendido en estas páginas apostar por una mirada histórica que intente ser más crítica, es decir, que sea capaz de cuestionar los presupuestos que determinan su propio pensar y que reflexione sobre sí misma. Las formas de narrar el país vehiculan los más diversos sentidos de interpretación, sentidos que forjan los vínculos que entablamos con los distintos actores sociales, los modos en que nos reconocemos como sujetos de una nación y las maneras en que resolvemos los conflictos. La posibilidad de este tipo de pensar histórico no pretende sólo dar cuenta de las vicisitudes del pasado, sino acercarse a él como fuerza interpretativa, en tanto inagotable creadora del presente.

\footnotetext{
${ }^{25}$ Bourdieu, "Sur les Rapports entre la Sociologie et l'Histoire en Allemagne et en France: Entretien avec Lutz Raphael", Actes de la Recherche en Sciences Sociales, 106-107 (marzo 1995): 117, citado en Varela, Nacimiento Mujer Burguesa, 34.
} 